\title{
A Study on the Aerodynamic Characteristics of Sustained Vowel and Continuous Speech Production of Female Voice Disorder Patients
}

\author{
Hwa Young Pyo \\ Department of Speech and Language Pathology, Chosun University, Gwangju, Korea
}

Correspondence: Hwa Young Pyo, PhD Department of Speech and Language Pathology, College of Health Science, Chosun University, 309 Pilmun-daero, Dong-gu, Gwangju 61452, Korea

Tel: +82-62-230-6188

Fax: +82-62-230-6271

E-mail: entvoice@chosun.ac.kr

Received: April 3, 2019

Revised: April 23, 2019

Accepted: May 15, 2019

\begin{abstract}
Objectives: Although it is well-known that the characteristics of sustained vowel and continuous speech are very different when evaluating voice problems, very little information has been reported on the aerodynamic aspects of these differences. The present study was performed to compare the aerodynamic characteristics of sustained vowel phonation and continuous speech production. Methods: Forty-three female patients with voice disorders produced a sustained vowel /a/ and continuous speech through paragraph reading, and their aerodynamic characteristics were analyzed using the 'Maximum Sustained Phonation' and 'Running Speech' programs of Phonatory Aerodynamic Systems (PAS). Results: There was no significant correlation between the sustained vowel and continuous speech in the time domain of the aerodynamic measurement results. However, there was a significant, but not high, correlation ( $r=-.521-.504)$ between the two speech tasks in the airflow rate and volume measurement results. Conclusion: We found that the correlation between the two tasks was significant, but not high. Therefore, in evaluating the aerodynamic characteristics of voice disorder patients, it is necessary to include continuous speech as well as a sustained vowel for meaningful and valid results.
\end{abstract}

Keywords: Voice disorder patients, Aerodynamic characteristics, Sustained vowel, Continuous speech
음성 문제의 평가는 다양한 문맥에서 이루어진다. 짧게는 연장 모음(sustained vowel)에서 길게는 연속발화(continuous speech) 에 이르기까지 다양한 문맥에서 청지각적, 음향학적, 공기역학적 평 가를 실시한다. 음성장애뿐만 아니라 말소리장애를 평가할 때도 음소 수준부터 시작하여 자발화 수준에 이르기까지 다양한 수준 에서 말소리를 평가한다. 음소, 음절, 자발화 등 다양한 발화 수준 은 수행 수준에 영향을 미쳐 언어학적 맥락의 수준에 따라 다른 수 행결과를 보이게 한다(Kim \& Shin, 2015).

음성장애의 청지각적 평가는 평정자의 귀를 통해 이루어지므로 귀가 들을 수 있는 모든 발화가 평가대상이 되기 때문에 별다른 어 려움 없이 다양한 수준을 고려한 평가를 시행할 수 있다. 그러나기 기를 이용한 평가는 다르다. 연장모음의 경우에는 별 문제가 없으 나 자음이 삽입되기 시작하면 자음의 특성이 평가결과에 영향을
미친다. 자음이 추가된 연속발화의 음향학적 평가 시 마찰음의 마 찰잡음이나 파열음의 파열잡음은 성도에서 만들어진 잡음이지만 성대에서 만들어진 잡음과 구분되어 분석기기에 입력되지 않기 때 문에 평가결과를 왜곡시킬 수 있다. 공기역학적 평가 시에는 모음 산출 시 성대를 통과하면서 배출되는 기류에 자음 산출 시 마찰 혹 은 파열로 인한 기류가 추가되므로 기류량이나 기류압, 기류속도 등을 측정하는 데 영향을 미칠 수 있다.

이러한 문제 때문에 대부분의 기기적 평가는 연장모음을 주로 사용하여 이루어진다. 음질을 기기적으로 분석하는 음향학적 평 가, 특히 시간에 따른 규칙성을 분석하는 주파수변동률(jitter)이나 진폭변동률(shimmer)의 측정은 성대의 주기적 진동이 나타나는 연장모음으로 실시된다. 공기역학적 평가는 대개 모음 /a/의 연장발 성을 이용하여 최대연장발성지속시간(maximum phonation time, 
$\mathrm{MPT}$ )이나 평균호기율(mean flow rate, MFR) 등을 측정한다. 연장 모음으로 기기적 평가를 실시하면 검사시간이 짧고 억양, 강세, 말 속도 등의 영향을 받지 않으며 방언의 영향을 덜 받는다는 장점이 있다(Gerratt, Kreiman, \& Garellek, 2016). 이에 비해 연속발화는 발화 주제, 주변 환경, 화자의 감정 상태 등 객관적 평가를 위해 통 제해야 할, 그러나 쉽게 통제할 수 없는 변수들이 다수 존재한다. 이 러한 요인들로 인해 대부분의 평가자는 음성평가 시 연장모음 중심 으로 평가를 진행한다.

그러나 연속발화에 비해 연장모음 과제는 일상적인 발화에서 나 타나는 역동적 측면을 반영하지 못한다는 단점이 있다. 이런 연유 로 음성장애 평가 시 연속발화에 대한 평가도 필요하다는 주장은 꾸준히 이어져 왔다. Maryn과 Roy (2012)는 청자가 연장모음에서 더 음성 문제가 심각한 것으로 지각하는 경향이 있다고 보고했으 며 Law 등(2012)은 모음보다 연속발화에서 더 높은 평정자 내 신뢰 도(intra-rater reliability)를 보인다고 보고했다. 이러한 차이로 인해 연장모음 분석과 더불어 연속발화 분석도 보완적으로 실시해야 한 다고 주장하고 있다.

음향학적 평가는 이러한 추세에 맞추어 카오스 이론에 근거하여 비주기적이고 무질서한 신호음을 분석하는 비선형 동적분석(nonlinear dynamic analysis)이나, 로그스펙트럼을 역변환하여 음성신 호를 분석하는 켑스트럼분석(cepstral analysis) 등을 도입하여 연 속발화를 분석한다. Zhang과 Jiang (2008)은 비선형 동적분석 중 상관차원(correlation dimension)과 콜모고로프 엔트로피(Kolmogorov entropy)를 시행한 결과 병적 음성과 정상 음성을 의미 있게 구분할 수 있다고 했고 Awan, Roy와 Dromey (2009)는 켑스트럼분 석이 다양한 음성장애 유형의 중증도 변별에 매우 유용하다고 했 다. 국내에서도 Yu, Choi, Choi와 Lee (2017)가 모음과 연속발화에 서 켑스트럼분석의 유용성을 비교하여 보고하는 등 다수의 연구 가 발표되었다.

그러나 연속발화를 이용한 공기역학적 측면의 연구는 음향학적 연구와 달리 매우 드물다. Pyo, Kim과 Baek (2014)이 Phonatory Aerodynamic System (PAS)을 이용하여 정상 화자와 음성장애 화 자의 문단낭독을 비교한 결과를 보고하였고 Gartner-Schmidt 등 (2015)이 연속발화 시 정상군과 편측성 성대마비 환자의 공기역학 적 특성을 비교해서 보고한 연구 정도이다. 연장모음과 연속발화 시 공기역학적 특성을 비교한 경우는 최근 Thiel, Yang, Crawley, Krishna와 Murry (2019)의/pa/ 음절을 반복했을 때와 문장을 산 출했을 때의 기류율 및 음성효율 비교 결과를 보고한 연구와 Gilman, Maira와 Hapner (2019)가 음성장애 화자의 연속발화의 기류 양상을 비교한 연구 등이 있다. 그동안 임상현장에서 주로 이루어
지는 공기역학적 평가는 위에서 언급한 것과 같이 연장모음을 이용 하여 MPT나 MFR을 측정하는 것이었다. PAS가 하위메뉴로 Running Speech를 포함하여 제작하면서부터 연속발화 분석을 보다 더 일상적으로 시행할 수 있게 되었으나 그 예는 아직도 매우 드물 다. 그러나 음성장애 화자의 평상시 발화 양상을 파악하기 위해서 는 연장모음뿐만 아니라 연속발화 시 공기역학적인 특성도 아울러 파악해야 할 필요가 있다. Gilman 등(2019)은 연장모음과 연속발 화를 비교한 연구에서 평상시 발화에서 나타나는 공기역학적 특성 을 연장모음의 분석결과만으로 판단하면 안된다고 지적하였다. 그 러므로 음성 문제를 보이는 대상자의 공기역학적 측면을 타당하게 측정하려면 평가 시 연장모음뿐만 아니라 연속발화를 활용한 평가 도 함께 이루어져야 하지만 실제로는 이를 뒷받침하고 활용할 만한 연구조차 매우 부족한 실정이다.

이에 본 연구에서는 음성장애 화자를 대상으로 공기역학적 평가 를 실시할 때 연장모음 분석을 통해 제공되는 측정치와 연속발화 분석을 통해 제공되는 측정치의 상관성을 비교해 보고자 하였다. 동일한 화자가 연장모음과 연속발화라는 서로 다른 과제를 산출할 때 그 공기역학적 특성이 어느 정도 상관성을 갖고 있는지 파악해 보고 그 결과를 통해 임상에서 공기역학적 평가를 실시할 때 발화 수준에 대해 어떤 고려를 해야 하는지 숙고해 보고자 하였다.

\section{연구방법}

\section{연구대상}

서울 소재 대학병원 이비인후과에서 양성 성대병변을 진단받고 임상경력 10 년 이상의 음성장애 전문가 2인이 GRBAS 척도평정을 실시하여 $\mathrm{G} 1$ 이상의 평정을 받은 18 세 이상의 성인 여성 43 명을 대 상으로 했다. 공기역학적 평가결과는 성별과 연령에 따라 다르게 나타나기 때문에 집단의 동질성을 확보하기 위해 성인 여성으로 한 정하였다. 이들의 평균연령은 38.12 세였고 평균 $\mathrm{G}$ 척도는 2.3 이었 다. 참여자에 대한 정보는 Table 1과 같다.

\section{연구절차}

\section{검사도구}

연장모음 및 연속발화의 공기역학적 평가를 위해 Phonatory Aerodynamic System (Model 6600; KayPENTAX, Montvale, NJ, USA)을 사용하였다. 연장모음의 공기역학적 분석은 PAS 중 Maximum Sustained Phonation을 이용하였고 연속발화의 공기역학적 분석은 PAS 중 Running Speech를 이용하였다. 
Table 1. Participants' characteristics ( $N=43$ )

\begin{tabular}{lc}
\hline Characteristic & N \\
\hline Age (yr) & 3 \\
$18-19$ & 5 \\
$20-29$ & 16 \\
$30-39$ & 13 \\
$40-49$ & 6 \\
$50-59$ & \\
Laryngeal pathology & 15 \\
Vocal nodules & 20 \\
Vocal polyp & 2 \\
Vocal nodule with polyp & 3 \\
Glottal cyst & 3 \\
Reinke's edema & \\
G scales & 6 \\
G1 & 19 \\
G2 & 18 \\
G3
\end{tabular}

\section{실험절차}

참여자로 하여금 연장모음 산출과 문단낭독 산출 과제를 수행하 도록 하였다. 이때 순서효과를 배제하기 위해 산출 과제의 순서는 참여자마다 무작위로 배열되도록 하였다.

연장모음의 공기역학적 평가를 위해 참여자에게 숨을 최대한 들 이마신 후 기류측정용 마스크를 얼굴에 밀착시키고 ‘아’ 모음을 최 대한 길게 연장발성하도록 하였다. 이때 검사자는 참여자에게, 최 대한 숨을 들이마시고 발성을 시작했는지, 평상시 음성강도와 음 도로 발성했는지, 최대한 길게 연장발성했는지 질문하여 참여자가 연장모음 과제를 올바로 수행했는지 확인하였다. 이 과정을 같은 방법으로 3 회 반복하도록 하였다.

연속발화의 공기역학적 평가를 위해 참여자에게 기류측정용 마 스크를 얼굴에 밀착시킨 후 A4 용지에 인쇄된 '가을' 문단을 낭독 하도록 하였다. 검사자는 참여자가 낭독하는 동안, GRBAS 척도 평 정을 위한 면담 시 파악한 평상시 음도와 강도로 낭독하고 있는지 확인하였으며 낭독이 끝난 후, 참여자에게 평상시대로 편안하게 읽 었는지 질문하여 이를 다시 한 번 확인하였다. 낭독하는 동안 잘못 읽거나 동일 음절이나 단어를 반복하는 등의 오류가 2 회 이상 나타 나면 다시 한 번 문단을 낭독하도록 하였다.

\section{분석방법}

\section{실험자료 분석}

Maximum Sustained Phonation을 이용한 연장모음의 분석은 3 회 반복한 발화 중 가장 긴 발화를 선택하여 이루어졌다. '아' 연장
모음의 시작과 끝을 분석구간으로 지정하여, 그 전체 지속시간을 나타내는 '최대발성지속시간(MPT)'-분석결과로 제시되는 것은 발성지속시간(phonation time)이지만 최대연장된 모음의 지속시 간이므로 여기서는 MPT로 사용한다-과 모음연장 중 가장 높은 호기량을 나타내는 '최대호기량(peak expiratory airflow)', 1초당 평균적으로 배출된 기류량을 나타내는 '평균호기량(Mean expiratory airflow)', 호기 시 배출된 전체 공기량을 나타내는 '호기체적 (expiratory volume)'을 분석하였다.

Running Speech를 이용한 연속발화의 공기역학적 분석은 전체 문단낭독 후 1 회 이하의 오류를 보인 발화자료를 대상으로 실시하 였다. 문단낭독의 시작과 끝을 분석구간으로 선정하여, 성대진동 을 동반한 발화의 지속시간을 나타내는 '발화지속시간(phonation time)', 전체 문단을 낭독하는 데 걸린 시간을 나타내는 '총지속시 간(total duration)', 총지속시간 중 기류가 배출된 지속시간을 나타 내는 '호기지속시간(expiratory airflow duration)'과 기류가 유입된 지속시간을 나타내는 '흡기지속시간(inspiratory airflow duration)', '최대호기량(peak expiratory airflow)', 연속발화 시 가장 높은 흡 기량을 나타내는 '최대흡기량(peak inspiratory airflow)', '호기체적 (expiratory volume)', 흡기 시 유입된 전체 공기량을 나타내는 ‘흡기 체적(inspiratory volume)'을 분석하였다(최대호기량이나 호기체 적 등 연장모음과 연속발화 분석 시 공히 나타나는 측정치가 있으 므로 이후 연장모음 및 연속발화 측정치를 구분해야 할 필요가 있 을 때 연장모음 측정치 뒤에는 '모음'을, 연속발화 측정치 뒤에는 '연속'을 붙이기로 한다).

\section{통계분석}

분석결과의 기술통계분석은 SPSS version 24.0으로 실시하였다. 기술통계분석을 이용하여 각 측정치의 평균 및 표준편차를 구하 였고, 연장모음 및 연속발화 측정치 간의 상관성을 검증하기 위해 피어슨 적률상관분석을 실시하였다.

\section{연구결과}

\section{연장모음 및 연속발화 공기역학적 측정치 분석 결과}

음성장애 화자를 대상으로 모음 / 아/를 3번 연장발성하도록 한 후 가장 길게 지속한 모음을 이용하여 공기역학적으로 분석한 결 과를 Table 2에 제시하였다.

Table 2에서 보는 바와 같이 최대발성지속시간은 평균 12.76초였 고 최대호기량과 평균호기량의 평균치는 각각 0.33 및 $0.20 \mathrm{~L} / \mathrm{sec}$ 였 으며 호기체적은 평균 $2.34 \mathrm{~L}$ 인 것으로 나타났다. 
Table 2. Results of aerodynamic analysis during sustained vowel phonation

\begin{tabular}{lc}
\hline & $M(S D)$ \\
\hline$M P T-V(s e c)$ & $12.76(4.19)$ \\
PEA-V $(L / s e c)$ & $0.33(0.13)$ \\
$M E A-V(L / s e c)$ & $0.20(0.09)$ \\
EV-V (L) & $2.34(0.76)$ \\
\hline
\end{tabular}

MPT-V = maximum phonation time-vowel; PEA-V = peak expiratory airflow-vowel; $M E A-V=$ mean expiratory airflow-vowel; $E V-V=$ expiratory volume-vowel.

Table 3. Results of aerodynamic analysis during continuous speech production

\begin{tabular}{lr}
\hline & $M(S D)$ \\
\hline PT-C (sec) & $29.87(3.58)$ \\
TD-C (sec) & $44.50(5.87)$ \\
EAD-C (sec) & $36.15(4.41)$ \\
IAD-C (sec) & $8.35(1.94)$ \\
PEA-C (L/sec) & $0.75(0.27)$ \\
PIA-C (L/sec) & $-1.98(0.51)$ \\
EV-C (L) & $5.77(3.05)$ \\
IV-C (L) & $-5.72(2.29)$ \\
\hline
\end{tabular}

$\mathrm{PT}-\mathrm{C}=$ phonation time-continuous speech; $\mathrm{TD}-\mathrm{C}=$ total duration-continuous speech; $E A D-C=$ expiratory airflow duration-continuous speech; $I A D-C=$ inspiratory airflow duration-continuous speech; $\mathrm{PEA}-\mathrm{C}=$ peak expiratory airflow-continuous speech; $\mathrm{PIA}-\mathrm{C}=$ peak inspiratory aiflow-continuous speech; $\mathrm{EV}-\mathrm{C}=$ expiratory volume-continuous speech; $\mathrm{IV}-\mathrm{C}=$ inspiratory volume-continuous speech.

'가을' 문단을 낭독했을 때의 공기역학적 측정치를 분석한 결과 는 Table 3과 같다.

문단낭독을 이용한 연속발화는 평균 44.50 초 동안 지속되었고 이 중 성대진동이 동반된, 즉 유성음이 차지한 평균시간은 29.87초 였다. 총지속시간 44.50 초 동안 호기지속시간은 평균 36.15초였고 흡기지속시간은 8.35 초였다. 최대호기량은 $0.75 \mathrm{~L} / \mathrm{sec}$ 인 데 비해 최 대흡기량의 절대값은 그보다 더 큰 $-1.98 \mathrm{~L} / \mathrm{sec}$ 였다. 호기체적과 흡 기체적의 평균은 각각 $5.77 \mathrm{~L}$ 와 $-5.72 \mathrm{~L}$ 로 비슷한 수치를 보였다.

\section{연장모음 및 연속발화 공기역학적 측정치 간의 상관성 분석 결과}

연장모음 발화와 연속발화의 공기역학적 측정 결과 간의 상관성 정도를 파악하기 위해 피어슨 상관분석을 실시하였고 그 결과를 Table 4에 제시하였다.

Table 4 와 같이 연속발화의 8 개 측정치 중 시간 영역과 관련된 4 개 측정치—즉, 발화지속시간-연속(PT-C), 총지속시간-연속(TDC), 호기지속시간-연속(EAD-C), 흡기지속시간-연속(IAD-C)는 연장모음의 측정치 4 개 모두와 유의한 상관을 보이지 않았다. 그 상관 정도도 -.250부터.096으로 매우 낮은 상관을 보이는 것으로
Table 4. Correlation analysis results of aerodynamic measurements between sustained vowel phonation and continuous speech production

\begin{tabular}{lcccc}
\hline & MPT-V & PEA-V & MEA-V & EV-V \\
\hline PT-C & .086 & -.250 & -.145 & -.063 \\
TD-C & .096 & -.059 & -.124 & -.049 \\
EAD-C & .093 & -.050 & -.058 & .034 \\
IAD-C & .079 & -.064 & -.245 & -.226 \\
PEA-C & -.105 & $.357^{*}$ & .270 & $.368^{*}$ \\
PIA-C & $.313^{*}$ & $-.385^{*}$ & $-.521^{* *}$ & $-.482^{* *}$ \\
EV-C & $-.317^{*}$ & $.378^{*}$ & $.504^{* *}$ & $.369^{*}$ \\
IV-C & $.304^{*}$ & $-.334^{*}$ & $-.439^{* *}$ & $-.317^{*}$ \\
\hline
\end{tabular}

$M P T-V=$ maximum phonation time-vowel; $P E A-V=$ peak expiratory airflow-vowel; MEA-V = mean expiratory airflow-vowel; EV-V=expiratory volume-vowel; $\mathrm{PT}-\mathrm{C}=$ phonation time-continuous speech; TD-C=total duration-continuous speech; $E A D$ $\mathrm{C}=$ expiratory airflow duration-continuous speech; $I A D-C=$ inspiratory airflow duration-continuous speech; PEA-C= peak expiratory airflow-continuous speech; PIA$\mathrm{C}=$ peak inspiratory airflow-continuous speech; $\mathrm{EV}-\mathrm{C}=$ expiratory volume-continuous speech; IV-C= inspiratory volume-continuous speech.

${ }^{*} p<.05,{ }^{* *} p<.01$.

나타났다. 연장모음 측정치 4 개와 연속발화 측정치 8 개, 총 32 개의 비교쌍 중 18 개(56.2\%)가. 30 이하의 상관을 보였다.

연속발화 측정치 중 최대호기량(PEA-C)은 모음연장발성 측정 치 중 최대호기량(PEA-V)과 호기체적(EV-V)에서 유의한 상관을 보였으나 그 정도는 중간 정도였다. 연속발화 측정치 중 최대흡기량 (PIA-C), 호기체적(EV-C), 흡기체적(IV-C)은 모음연장발성 측정 치 4 개 모두와 유의한 상관을 보였다. 호기체적-연속과 평균호기 량-모음은 중간 정도의 정적 상관을 보였으며 $(r=.504)$, 최대흡기 량-연속과 평균호기량-모음 $(r=-.521)$, 최대흡기량-연속과 호기체 적-모음 $(r=-.482)$, 흡기체적-연속과 평균호기량-모음 $(r=-.439)$ 역 시 중간 정도의 부적 상관을 보였다.

\section{논의 및 결론}

본 연구에서는 연장모음과 연속발화의 공기역학적 특성을 비교 해 보기 위해 음성장애 화자 43명을 대상으로 PAS 중 연장모음 분 석을 위한 Maximum Sustained Phonation과 연속발화 분석을 위 한 Running Speech를 실시하였다. 연장모음 및 연속발화측정치의 상관분석을 실시한 결과, 연장모음의 측정치 4 개(최대발성지속시 간, 최대호기량-모음, 평균호기량, 호기체적-모음)와 연속발화 측정 치 중 시간 영역과 관련된 측정치 4 개(발화지속시간-연속, 총지속 시간-연속, 호기지속시간-연속, 흡기지속시간-연속)는 서로 유의한 상관을 보인 측정치가 없었으며 그 상관 정도도 매우 낮았다. 연속 발화에서 시간 영역의 측정치 4 개를 제외한 최대호기량-연속, 최대 
흡기량-연속, 호기체적-연속과 흡기체적-연속은 두 개의 비교쌍(최 대호기량-연속과 최대발성지속시간-모음, 최대호기량-연속과 평균 호기량-모음)을 제외하고는 모두 유의한 상관(-.521부터 .504까지) 을 보였다. 그러나 그 정도는 대체로 미약하였다. 가장 높은 상관계 수도 -.521로 이 정도의 상관계수는 Sung과 $\mathrm{Si}$ (2014)에 따르면 '상 관이 있다' 정도의 높지 않은 상관성을 보였다.

연장모음과 연속발화의 상관성을 분석한 결과 유의한 상관을 보 이며 .30 이상의 상관성을 보인 비교쌍이 총 32 개 중 14 개(43.8\%)였 고. 35 이상의 상관성을 보인 비교쌍은 9 개(28.1\%)였다. 상관 정도를 .35 이상으로 높여 비교하면 연장모음 측정치 중 시간 관련 측정치 인 MPT는 연속발화 측정치 중 어떤 것과도. 35 이상의 상관을 보이 지 않았다. 즉, 연장모음의 시간 관련 측정치는 연속발화의 모든 측 정치와 매우 낮은 상관을 보였다.

공기역학적 평가는 화자가 음성 산출을 얼마나 편하게 '지속'할 수 있는지에 대한 정보를 제공해주는 대표적 측정치이다. 공기역학 적 평가 측정치 중 대표적 시간 관련 측정치인 MPT는 Lee, Stemple, Glaze와 Kelchner (2004)가 발표한 음성선별검사인 Quick Screen for Voice 검사에서도 활용될 정도로 널리 사용되고 있다. $\mathrm{MPT}$ 는 비용이 적게 들고 빠르게 측정할 수 있는 비침습적 평가방 법으로 정상 화자와 음성장애 화자를 신뢰롭게 구분할 수 있으며 여러 번 반복해도 학습효과나 음성피로가 영향을 미치지 않는 유 용한 방법이다(Speyer et al., 2010). 그러나 MPT가 음성장애 화자 의 공기역학적 특성을 평가하는 데 얼마나 '타당한' 도구인가에 대 해서는 의견이 다양하다. Gartner-Schmidt 등(2015)은 MPT는 기 본적으로 기류를 측정하는 것이 아니기 때문에 공기역학적 측정치 라고 보기 어렵고 따라서 연속발화 시 나타나는 일련의 사건을 객 관적으로 측정할 수 없다고 하였다. 본 연구결과에서도 MPT가 연 속발화의 측정치와 유의하다고 해도 그 상관성은 낮았기 때문에 $\mathrm{MPT}$ 가 평상시 발화의 공기역학적 특성을 반영한다고 보기 어렵 다는 선행문헌의 주장과 맥을 같이하고 있다.

본 연구결과 중 가장 높은 부적 상관을 보인 비교쌍은 연장모음 의 평균호기량과 연속발화의 최대흡기량(-.521)이었고 가장 높은 정적 상관을 보인 쌍은 연장모음의 평균호기량과 연속발화의 호기 체적(.504)이었다. 두 경우 모두 연장모음의 평균호기량이 포함되어 있는데 연장모음의 평균호기량은 연속발화의 흡기체적과도 다른 비교쌍에 비하면 높은 상관성(-.439)을 보였다. 이를 통해 연장모음 의 측정치 중에서는 평균호기량이 평상시 발화의 공기역학적 특성 을 비교적 잘 반영하는 것으로 나타났다.

연속발화의 측정치 중에서는 최대흡기량과 호기체적 및 흡기체 적이 연장모음 측정치 4 개 모두와 유의한 상관을 보였다. 이 중 최
대흡기량은 연장모음 4 개 측정치 중 MPT를 제외한 3 개 측정치(최 대호기량, 평균호기량, 호기체적)에서 다른 연속발화 측정치보다 .35 이상의 높은 상관성을 보였다. 이에 비해 연속발화의 최대호기 량은 연장모음의 최대호기량과 호기체적에서 유의하지만 낮은 상 관(.357, .368)을 보였다. Running Speech를 이용한 연속발화 측정 치 중에는 평균호기량이 없고 최대흡기량과 최대호기량만 제시되 는데, 연속발화의 호기량에는 자음 산출 시 동반되는 파열이나 마 찰이 기류량에 포함되어 있기 때문에 상대적으로 연장모음의 호기 량과는 별다른 상관을 보이지 않은 것으로 판단된다.

공기역학적 평가 시 연속발화 과제를 포함하여 진행한 연구는 많 지 않다. 그중 일부를 보면, Pyo 등(2014)은 Running Speech를 이 용한 문단낭독 시 정상 화자와 음성장애 화자의 호흡단락을 비교 하였다. 동일한 길이의 문단을 낭독할 때 음성장애 화자에 비해 정 상 화자의 평균호흡단락수가 유의하게 적었고 호흡단락당 평균음 절수가 유의하게 더 많았음을 보고하면서 연속발화를 통한 공기역 학적 분석결과가 정상 음성과 병적 음성을 의미있게 구분할 수 있 다고 하였다. Gilman 등(2019)은 PAS의 Comfortable Sustained Phonation과 Running Speech를 이용하여 음성장애 화자의 연장 모음, 문단낭독 전체, 문단낭독 중 모음 부분의 공기역학적 특성을 비교하였다. 그 결과 연장모음의 기류량과 문단낭독 중 모음 부분 의 기류량에는 유의한 차이가 있었으나 연장모음과 문단낭독 전체, 그리고 문단낭독 중 모음 부분과 문단낭독 전체의 기류량 사이에는 유의한 차이가 없다고 했다. 이 결과를 바탕으로 이들은 공기역학 적 특성을 평가할 때 다른 방법보다 현저히 뛰어난 유일한 평가방 법은 없다고 지적하였다. Thiel 등(2019)은 정상 화자가 음절 산출 시 모음에서 측정되는 기류율(airflow rate)과 문장산출 시 측정되 는 기류율을 비교하였다. 그 결과 문장산출의 기류율이 유의하게 높았다고 보고하면서 기류율을 측정할 때 어떤 발화를 평가 과제 로 사용하느냐가 결정적 요인(critical factor)이 된다고 주장하였다.

아직 음성장애 평가현장에서 공기역학적 평가 시 연속발화 과제 를 사용하는 경우는 흔하지 않다. 본 연구는 공기역학적 평가 시 연 장모음과 연속발화 측정치의 상관성을 비교하여 상관성이 대체로 .30-.50 정도의 높지 않은 상관을 보였음을 보고하였고 이를 통해 음성장애 화자의 공기역학적 평가 시 기존의 연장모음 분석뿐 아니 라 연속발화의 분석도 함께 시행하는 것이 평가의 타당성을 높일 수 있음을 제시하였다. 또한 연장모음 중에서는 평균호기량이 연속 발화 측정치와, 연속발화 중에서는 최대흡기량이 연장모음 측정치 와 상관성이 비교적 높게 나타났다고 보고하여, 연속발화를 평가 과제로 활용하기 어려운 때, 예를 들어 사용하는 공기역학적 평가 도구에 연속발화 분석 메뉴가 없을 때에는 연장모음 측정치 중 평 
균호기량의 측정치를 적극 활용하도록 제안하고 있다.

그러나 본 연구는 연구에 참여한 대상자 수가 적고 여성 화자만 을 대상으로 하고 있다는 제한점을 갖고 있다. 연구대상을 남성으 로 확대하고 성인뿐 아니라 아동 혹은 노인 등 다양한 연령층으로 확대한 추후연구가 이어져야 할 것이다. 또한 본 연구는 음성장애 화자만을 대상으로 하고 있는데 정상 성대를 가진 참여자를 대상 으로 한 후속연구도 진행되어야 한다. 즉 정상 화자의 연장모음 및 연속발화 측정치 간의 상관성을 비교하여 그 양상이 음성장애 화 자와 어떤 차이와 공통점을 보이는지 비교해 보는 과정이 필요하다.

본 연구는 음성평가 시 공기역학적 특성을 올바르게 파악하려면 연장모음뿐 아니라 연속발화도 포함해야 한다고 제안하고 있다. 임 상에서 이를 적절히 활용하려면 아직도 많은 연구가 필요하다. 선 행연구에서 음성장애 화자와 정상 화자의 호흡단락을 비교한 연구 가 있는데 두 집단의 연속발화 측정치를 비교하는 후속연구도 필 요하다. 연속발화를 평가 과제로 할 때 항상 대두되는 문제는 어떤 발화 과제를 사용할 것인가 하는 문제이다. 어떤 주제의, 어떤 형식 을 가진 발화 과제를, 어떤 길이로 사용하는 것이 임상에서 사용하 기 적절한지에 대한 연구도 추후연구로 진행되어야 한다.

\section{REFERENCES}

Awan, S. N., Roy, N., \& Dromey, C. (2009). Estimating dysphonia severity in continuous speech: application of a multi-parameter spectral/cepstral model. Clinical Linguistics \& Phonetics, 23(11), 825-841.

Gartner-Schmidt, J. L., Hirai, R., Dastolfo, C., Rosen, C. A., Yu, L., \& Gillespie, A. I. (2015). Phonatory aerodynamics in connected speech. The Laryngoscope, 125(12), 2764-2771.

Gerratt, B. R., Kreiman, J., \& Garellek, M. (2016). Comparing measures of voice quality from sustained phonation and continuous speech. Journal of Speech, Language, and Hearing Research, 59(5), 994-1001.
Gilman, M., Maira, C., \& Hapner, E. R. (2019). Airflow patterns of running speech in patients with voice disorders. Journal of Voice, 33(3), 277-283.

Kim, S. J., \& Shin, J. Y. (2015). Speech sound disorders. Seoul: Sigmapress.

Law, T., Kim, J. H., Lee, K. Y., Tang, E. C., Lam, J. H., van Hasselt, A. C., \& Tong, M. C. (2012). Comparison of rater's reliability on perceptual evaluation of different types of voice sample. Journal of Voice, 26(5), 666.e13-666. e21.

Lee, L., Stemple, J. C., Glaze, L., \& Kelchner, L. N. (2004). Quick screen for voice and supplementary documents for identifying pediatric voice disorders. Language, Speech, and Hearing Services in Schools, 35(4), 308-319.

Maryn, Y., \& Roy, N. (2012). Sustained vowels and continuous speech in the auditory-perceptual evaluation of dysphonia severity. Jornal da Sociedade Brasileira de Fonoaudiologia, 24(2), 107-112.

Pyo, H., Kim, S., \& Baek, S. (2014). A comparison study of breath groups during reading paragraph tasks in normal adults and adult patients with voice disorders: a preliminary study. Phonetics and Speech Sciences, 6(4), 181-187.

Speyer, R., Bogaardt, H. C., Passos, V. L., Roodenburg, N. P., Zumach, A., Heijnen, M. A., ... \& Brunings, J. W. (2010). Maximum phonation time: variability and reliability. Journal of Voice, 24(3), 281-284.

Sung, T., \& Si, G. (2014). Research methodology (2nd ed.). Seoul: Hakjisa.

Thiel, C., Yang, J., Crawley, B., Krishna, P., \& Murry, T. (2019). Aerodynamic characteristics of syllable and sentence productions in normal speakers. Journal of Voice, 33(3), 297-301.

Yu, M., Choi, S. H., Choi, C. H., \& Lee, K. (2017). Usefulness of cepstral acoustic index for estimating objective dysphonia severity. Communication Sciences \& Disorders, 22(3), 587-596.

Zhang, Y., \& Jiang, J. J. (2008). Acoustic analyses of sustained and running voices from patients with laryngeal pathologies. Journal of Voice, 22(1), $1-9$. 


\section{국문초록}

\section{음성장애 성인 여성화자의 연장모음 및 연속발화 산출 시 공기역학적 특성 연구 표화영}

조선대학교 언어치료학과

배경 및 목적: 음성장애 화자를 평가할 때 연장모음과 연속발화가 보이는 특성이 서로 다름은 익히 알려져 있으나 공기역학적 측면에 서의 이러한 연구는 매우 드물다. 이에 본 연구는 음성장애 화자의 공기역학적 특성이 연장모음과 연속발화 시 어떤 상관을 보이는지 알아보고자 하였다. 방법: 43 명의 음성장애 여성화자로 하여금/ㄱ/ / 모음의 연장발성과 '가을' 문단 낭독을 하도록 하였다. 이를 Phonatory Aerodynamic System의 Maximum Sustained Phonation과 Running Speech 프로그램을 이용하여 연장모음 및 연속발화의 공기 역학적 측면을 분석하고 측정치 간의 상관성을 비교하였다. 결과: 공기역학적 측정치 중 시간 관련 영역 측정치는 연장모음과 연속발화 간의 유의한 상관이 없었다. 기류량과 기류체적 관련 영역 측정치는 유의한 상관을 보이기는 했으나 그 상관의 정도가 높지는 않았다 $(r=-.521-.504)$. 논의 및 결론: 연구 결과, 공기역학적 측면에서 연속발화 측정치와 연장모음 측정치 간의 상관성은 유의하지 않거나 유 의해도 상관성이 높지 않은 것으로 나타났다. 그러므로 임상적 의미가 있는 공기역학적 평가를 실시하기 위해서는 연장모음뿐만 아니 라 연속발화 과제도 함께 고려해야 할 것이다.

핵심어: 음성장애 화자, 공기역학적 특성, 연장모음, 연속발화

\section{참고문헌}

김수진, 신지영(2015). 말소리장애. 서울: 시그마프레스.

성태제, 시기자(2014). 연구방법론(2판). 서울: 학지사.

유미옥, 최성희, 최철희, 이경재(2017). 객관적인 음 성장애 중증도 측정을 위한 캡스트럼 음향 지표의 유용성. Communication Sciences \& Disorders, 22(3), 587-596.

표화영, 김소연, 백승국(2014). 정상 성인 화자와 음성장애 성인 화자의 문단낭독 시 호흡단락에 대한 비교 연구: 예비연구. 말소리와 음성과학, 6(4), 181-187.

\section{ORCID}

표화영(https://orcid.org/0000-0003-3697-2111) 